WANL - TME - 905

\title{
TITLE: ACCEPTANCE TEST SPECIFICATIONS FOR PRESSURE TRANSDUCERS
}

Date: September 23, 1964

Author(s):

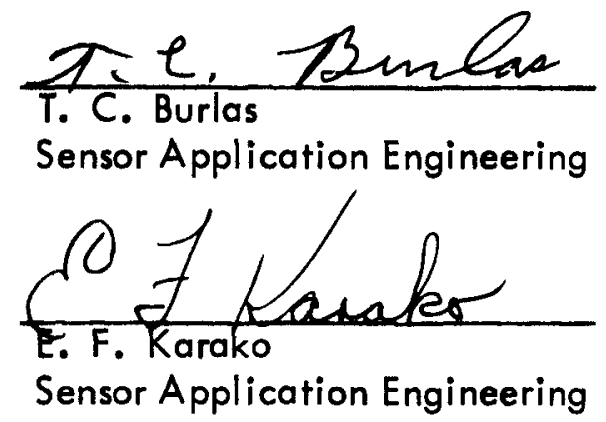

Approved by:

$$
\text { Rowpen }
$$
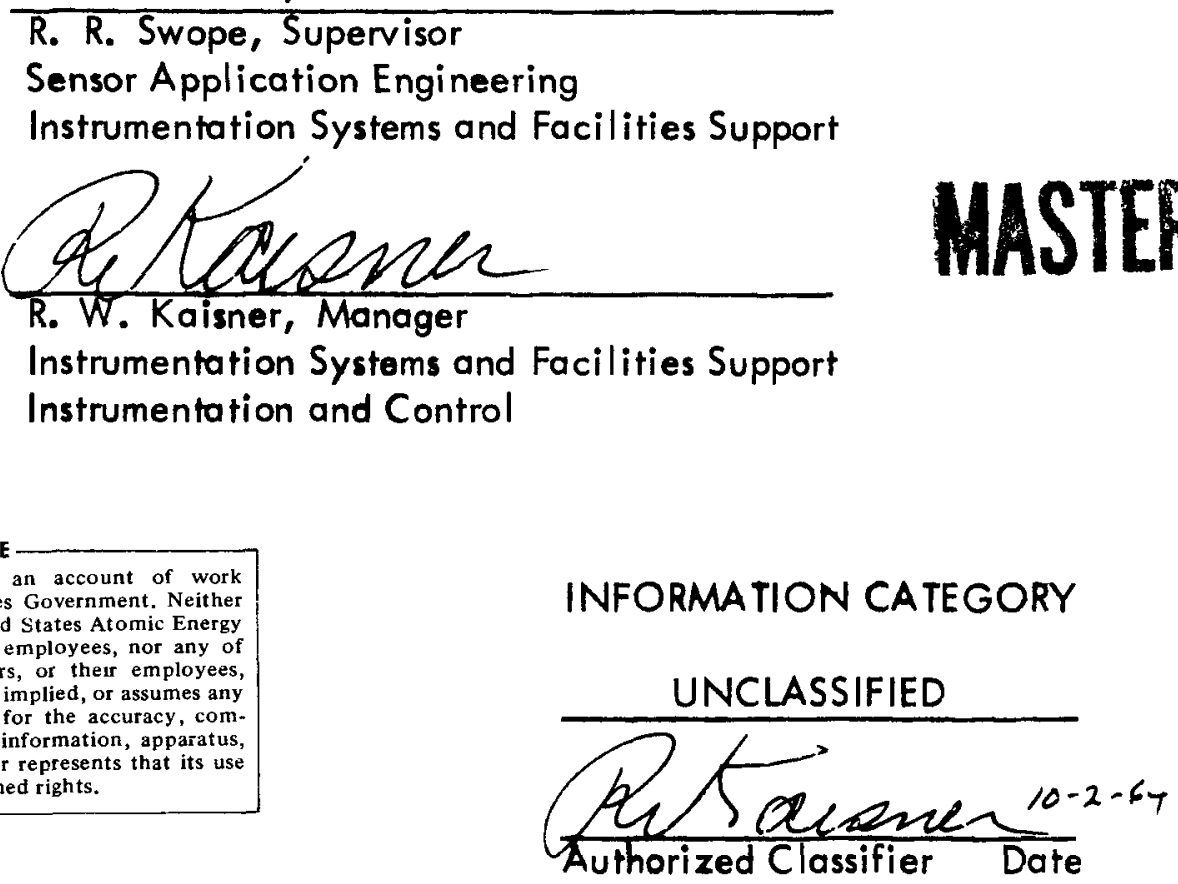


\section{DISCLAIMER}

This report was prepared as an account of work sponsored by an agency of the United States Government. Neither the United States Government nor any agency Thereof, nor any of their employees, makes any warranty, express or implied, or assumes any legal liability or responsibility for the accuracy, completeness, or usefulness of any information, apparatus, product, or process disclosed, or represents that its use would not infringe privately owned rights. Reference herein to any specific commercial product, process, or service by trade name, trademark, manufacturer, or otherwise does not necessarily constitute or imply its endorsement, recommendation, or favoring by the United States Government or any agency thereof. The views and opinions of authors expressed herein do not necessarily state or reflect those of the United States Government or any agency thereof. 


\section{DISCLAIMER}

Portions of this document may be illegible in electronic image products. Images are produced from the best available original document. 


\section{ACCEPTANCE TEST SPECIFICATIONS FOR PRESSURE TRANSDUCERS}

\subsection{SCOPE}

This document outlines the Westinghouse Astronuclear Laboratory (WANL) specifications and procedures for acceptance testing of differential and absolute pressure transducers. All pressure transducers used for reactor instrumentation shall meet the requirements of this specification before being accepted.

\subsection{PERFORMANCE OF TESTS}

2. 1 The acceptance testing will be performed by the Standards Laboratory and/ or Sensor Application Engineering, per the requirements of this specification.

2.2 All data taken shall be approved by Quality Control and kept as a permanent record for the transducer. A copy of the data sheet shall be dated, signed by the technician and forwarded to the responsible Sensor Application Engineer.

2.3 No deletions changes or omission of tests covered by this specification shall be made without the approval of Sensor Application Engineering and Quality Control Engineering.

2. 4 Since the requirements for acceptance resting and calibration testing overlap, the two tests may be performed simultaneously. However, this will require coordination and approval between Sensor Application Engineering and Quality Control Engineering as to specification limits, test equipment error, etc. 
2.5 When out-of-spec readings occur, the transducer shall be sent to ERB for disposition. All out=of-spec readings shall be circled on the data sheet.

2.6 Quality Control will instigate an RIR which will reflect any contractual information that is lacking and/or NMDR action required. Although the RIR is not completed at this time, a Xerox copy should accompany the units.

\subsection{REFERENCE DOCUMENTS AND SPECIFICATIONS}

The following documents and specifications per their latest revisions are a reference for this specification. In any conflict between this specification and those documents, paragraph 2.3 shall apply.

WANt-E -675440

WANL-E-675529
Pressure Transducers for Radiation Environmert, Variable Reluctance Type

Pressure Transducers for Radiation Environ-

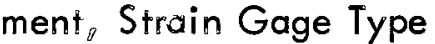

\section{0 TEST EQUIPMENT REQUIREMENTS}

The following is a list of test equipment required to perform acceptance testing of pressure transducers. Additional and/or equivalent test equipment can be substituted if necessary.

Excitation Source

Pressure Gages (Heise) Dead Weight voltage stability better than $0.1 \%$ frequency stability better than $1 \%$

$0.1 \%$ or better 
AC Differential Voltmeter

(John Fluke)

or Digital Voltmeter

Megohmmeter

Impedance Bridge (RLC)

(John Fluke, Model 710A)
$0.2 \%$ or better

range, $50 \mathrm{~V} D C$ to $500 \mathrm{~V} \mathrm{DC}$

Crescent-East Demodulator Channel

Symmetry Sensing Module

$.2 \%$ or better

DC Digital Voltmeter

\subsection{TEST PROCEDURE}

The following procedure describes the sequence of operations necessary to perform the acceptance testing of pressure transducers.

5. 1 Record all preliminary data on the applicable data form (i.e., manufacturer, serial number, range, etc.).

5.2 Measure and record, with an impedance bridge, the input and output resistance/impedance of each transducer. Record on data sheet as $R+i X_{L}$ at operating frequency. Check wire terminations with applicable specification control drawing. For piezoelectric type, measure and record output capacitance.

5.3 Measure and record the insulation resistance between all transducer leads or terminals in parallel and transducer case. It shall be 50 megohms minimum at $50 \mathrm{~V} D C$.

5.4 Connect the transducer to the pneumatic pressure system and the applicable excitation voltage source. (See applicable E-Specification.) 
5.5 Energize the test system, then set up the excitation voltage(s), where applicable, for the particular transducer being tested. Allow approximately thirty (30) minutes warmup, then reset any critical voltages.

5.5. I For variable reluctance type, setup the demodulator by peaking the phase and adjusting zero and/or operating range output(s).

5.5.2 For strain gage type, adjust associated excitation and readout equipment for zero and operating range output.

5.6 Whenever possible, the transducer should be acceptance tested through the same type of leads, demodulators, amplifiers, test equipment, etc. that was used by the vendor.

5.7 For acceptance testing of pressure transducer, the following definitions apply.

5.7.1 Test step - each voltage measurement recorded at a level of input pressure.

5.7.2 Test cycle - one full range excursion of the pressure transducer in the increasing and decreasing direction, consisting of all the calibration steps.

5.7.3 Test run - a minimum of three (3) cycles taken at a given environmental condition, i.e., temperature, radiation, etc.

5.8 Perform a room temperature test run on the transducer.

5.8. 1 Measure and record the output voltage at each step of each cycle. Each cycle of a test run for a particular pressure transducer shall 
begin at $0 \% F R$ pressure, increase to $120 \% F R$ pressure and return to $0 \% \mathrm{FR}^{*}$. Use $20 \% \mathrm{FR}$ steps between $0 \%$ and $120 \%$.

NOTE: In the event a slight input pressure overshoot occurs at any particular step, this step must be reapproached from the previous step before that particular voltage is recorded.

5.9 Measure and record the $0 \%$ and $100 \%$ FR outputs of the transducer at the extremes of the compensated temperature range as called out in the applicable E-Specification.

\subsection{PERFORMANCE REQUIREMENTS}

6.1 RANGE: The full range of each transducer shall be in accordance with the applicable WANL specification control drawing.

6.2 LINEARITY AND HYSTERESIS: Calculate and record, for each run, the error resulting from the effects to linearity and hysteresis. These errors shall be that percentage of variations of the full range output taken from a straight line drawn through the test points over the full test range.

NOTE: To calculate linearity and hysteresis:

(a) Determine the average output at each step for each run.

(b) Subtract algebraically, when applicable, the average outputs resulting from $0 \%$ and $100 \%$ inputs. This resultant is the full range sensitivity.

*CAUTION: When testing absolute units at gage pressure, the $120 \%$ overrange may be too much for the transducer. Therefore, units ranged at 500 psia and under, perform test to $100 \%$ FR maximum. 
(c) Determine the linear change in output by dividing full range output by the number of increasing even test steps. This determines the straight line between the $0 \%$ and $100 \%$ full range output.

(d) Determine the worst case of linearity and hysteresis from the straight line between $0 \%$ and $100 \%$ full range output. This can be one of two cases: (1) all points lie on one side of the straight line, and (2) the points lie on both sides of the straight line. The maximum voltage difference between the straight line and the hysteresis curve (1), or the maximum voltage difference between the increasing and decreasing hysteresis curve (2), is the worst case of linearity and hysteresis. This maximum voltage difference is designated as $L$.

(e) Linearity and hysteresis, \%FR $=\frac{L}{2(S)} \times 100$ where; $F R=$ full range, as determined at 6.2(b).

$$
\begin{aligned}
S= & \text { sensitivity at a particular environmental } \\
& \text { test run. }
\end{aligned}
$$

6.2. 1 The combined error resulting from the effects of nonlinearity and hysteresis shall not exceed the limits called out in the applicable E-Specification.

6.3 SENSITIVITY: The sensitivity of each type of pressure transducer shall be within the minimum and maximum limits specified on the applicable WANL specification control drawings and equipment specifications. 
6.3.1 Determine the sensitivity by calculating and recording for each test run the average output observed from 100\% input. (If applicable, subtract algebraically the average outputs for $0 \%$ and $100 \%$ inputs.)

6.4 RESIDUAL UNBALANCE: The residual unbalance of the transducer shall be within the limits specified in the applicable WANL equipment specification.

6.4.1 To determine residual unbalance, calculate and record the average output voltage observed at zero applied pressure.

NOTE: For absolute pressure transducers, record whether zero psia or zero psig is used.

6.5 REPEATABILITY: The output shall be repeatable, within the limits specified in the applicable equipment specifications for three (3) consecutive operating range excursions performed under identical conditions over the operating temperature range.

6.5.1 To determine the repeatability, calculate and record, in \% of full range, the maximum deviation from the average value of the three continuous full range excursions under identical conditions, i. e., establish the maximum output voltage difference between cycles at each calibration step. This maximum deviation shall not exceed $\pm 0.10 \%$ full range.
6.5 .1 .1
Repeatability, \%FR $=\frac{M}{2(S)} \times 100$
where; $F R=$ full range, as determined at $6.2(b)$. 


$$
\begin{aligned}
M= & \text { maximum output voltage difference } \\
& \text { between cycles, at each calibration } \\
& \text { step for the given run. } \\
S= & \text { sensitivity. }
\end{aligned}
$$

6.6 THERMAL ZERO SHIFT: Measure and record the thermal zero shift of the transducer over its compensated temperature range. (See applicable ESpecification for specification limits.)

6.6.1 Thermal zero shift, \%FR $/{ }^{\circ} \mathrm{F}=\left|\frac{V_{T 1}-V_{T 2}}{S_{R T}\left(T_{1}-T_{2}\right)}\right| \times 100$

where; $F R=$ full range, as determined at 6.2(b).

$$
\begin{aligned}
V_{T 1}-V_{T 2}= & \text { difference in residual unbalance of the } \\
& \text { transducer at } T_{1} \text { and } T_{2} . \\
T_{1}-T_{2}= & \text { the compensated temperature range of the } \\
& \text { transducer }\left({ }^{\circ} \mathrm{F}\right) . \\
S_{R T}= & \text { sensitivity at room temperature (volts). }
\end{aligned}
$$

6.7 THERMAL SENSITIVITY SHIFT: Measure and record the thermal coefficient of sensitivity of the transducer over its compensated temperature range. (See applicable E-Specification for specification limits.)

6.7.1 Thermal sensitivity shift, $\% /{ }^{\circ} \mathrm{F}=\left|\frac{\mathrm{S}_{1}-\mathrm{S}_{2}}{\mathrm{~S}_{\mathrm{RT}}\left(\mathrm{T}_{1}-\mathrm{T}_{2}\right)}\right| \times 100$

$$
\text { where; } \begin{aligned}
S_{1} & =\text { sensitivity at } T_{1} \text { (volts). } \\
S_{2} & =\text { sensitivity at } T_{2} \text { (volts). } \\
S_{R T} & =\text { sensitivity at room temperature (volts). } \\
T_{1}-T_{2} & =\text { the compensated range of the transducer }\left({ }^{\circ} \mathrm{F}\right) .
\end{aligned}
$$




\begin{tabular}{|c|c|}
\hline MANRFACrunta & WAMU E-SPEC NO. \\
\hline MANGNACTISTR SERIN NO. & 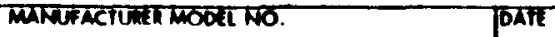 \\
\hline
\end{tabular}

a. morcate me and accuract of marsical test stimurus

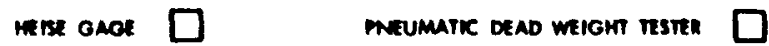

sereirn orme

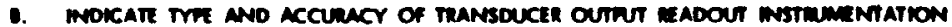

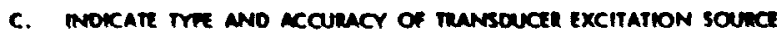

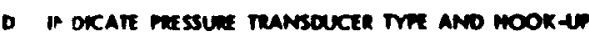

FiG. 1

STRAIN GAGE

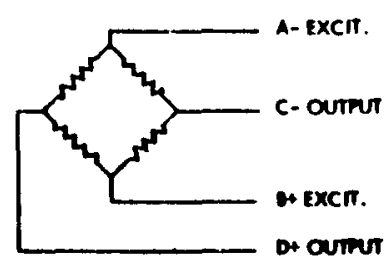

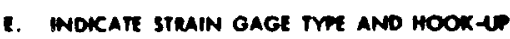

110 1

Full Meloce

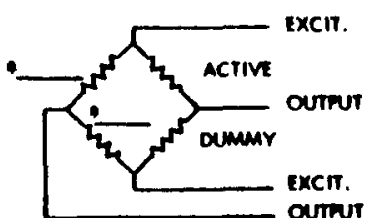

FIG. $2 \square$

VARtaue retuctance

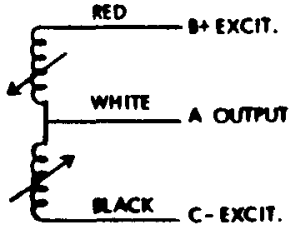

SERIAL MUMB:R

$m$

$m$

senal Nume accuracr $\checkmark$

accuracr. accunacr
1040

Onmk tvor

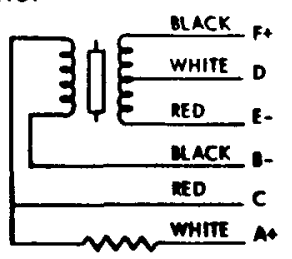

SECONDANY

(OUTnur)

(a)

mounr
- note: inoicate mhich is active and dumar ano molartr of each tead

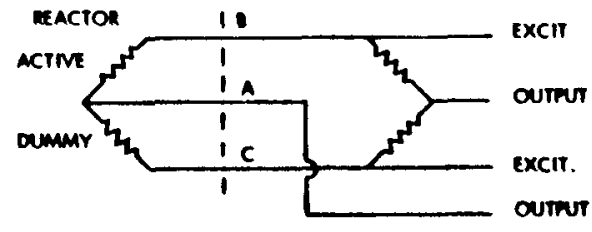

QUARTER BRIDGE

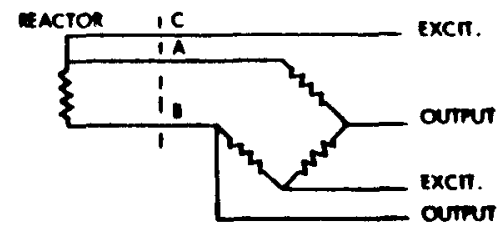

oumr

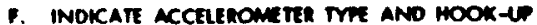

FiG. 1

mezotternk

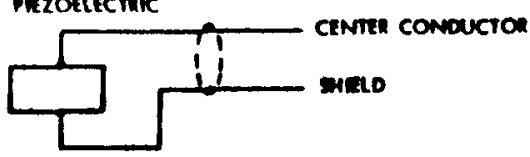

F10. $2 \square$

DECTMO-MENANICA
G. DISMACEMENT (RVDT) HOOK-UP

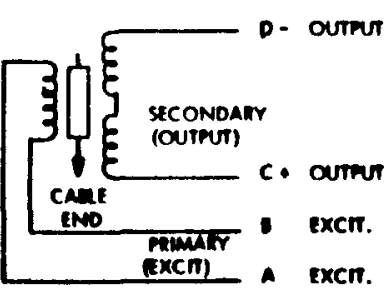

N. Nonts 
A: I PTANCE DATA REPORT-TRANSDUCER, PRESSURE $\square$ OR DISPLACEMENT $\square$

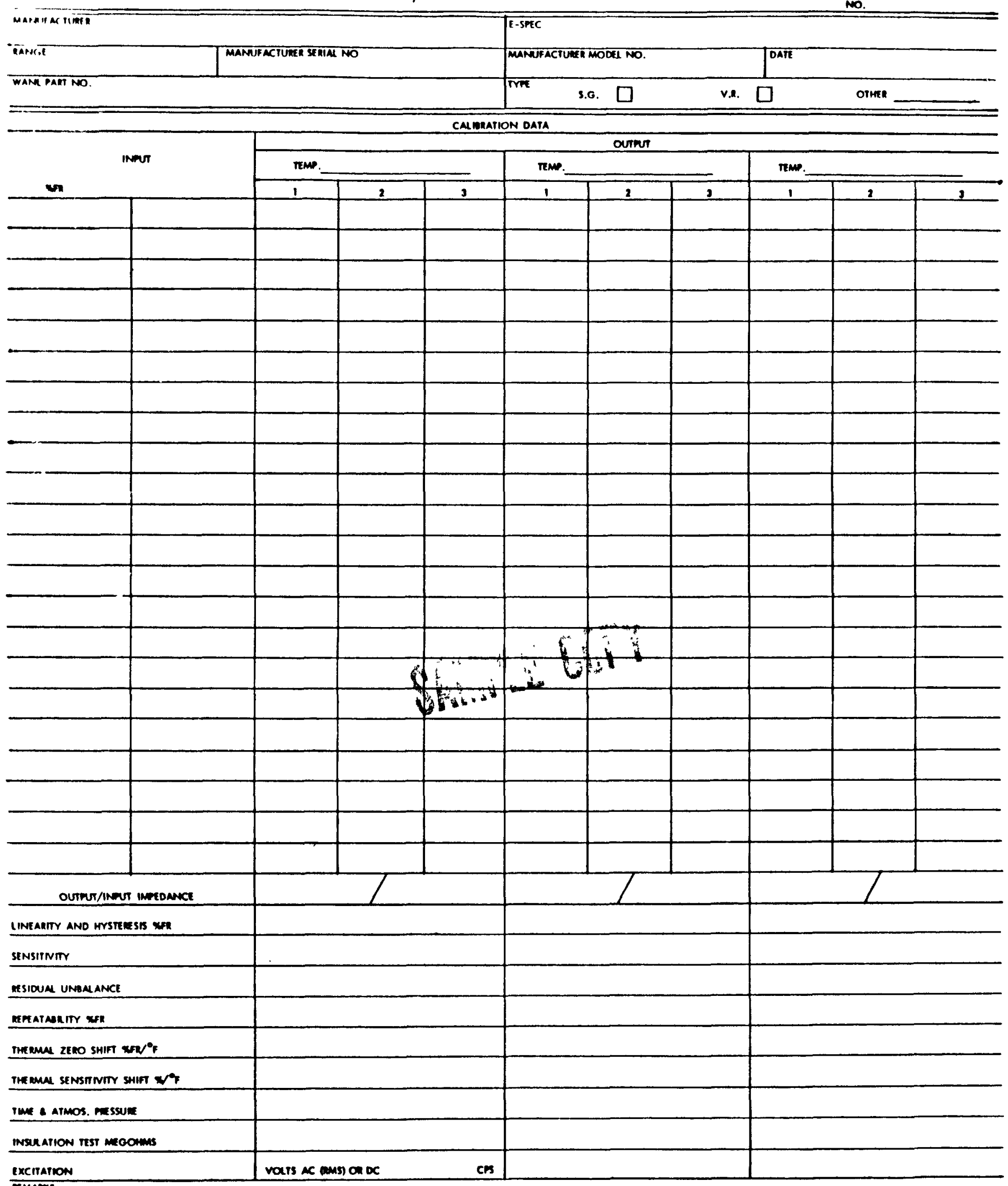


Pigure I

Variable Reluctance or IVDT Type Prosoure Transducors

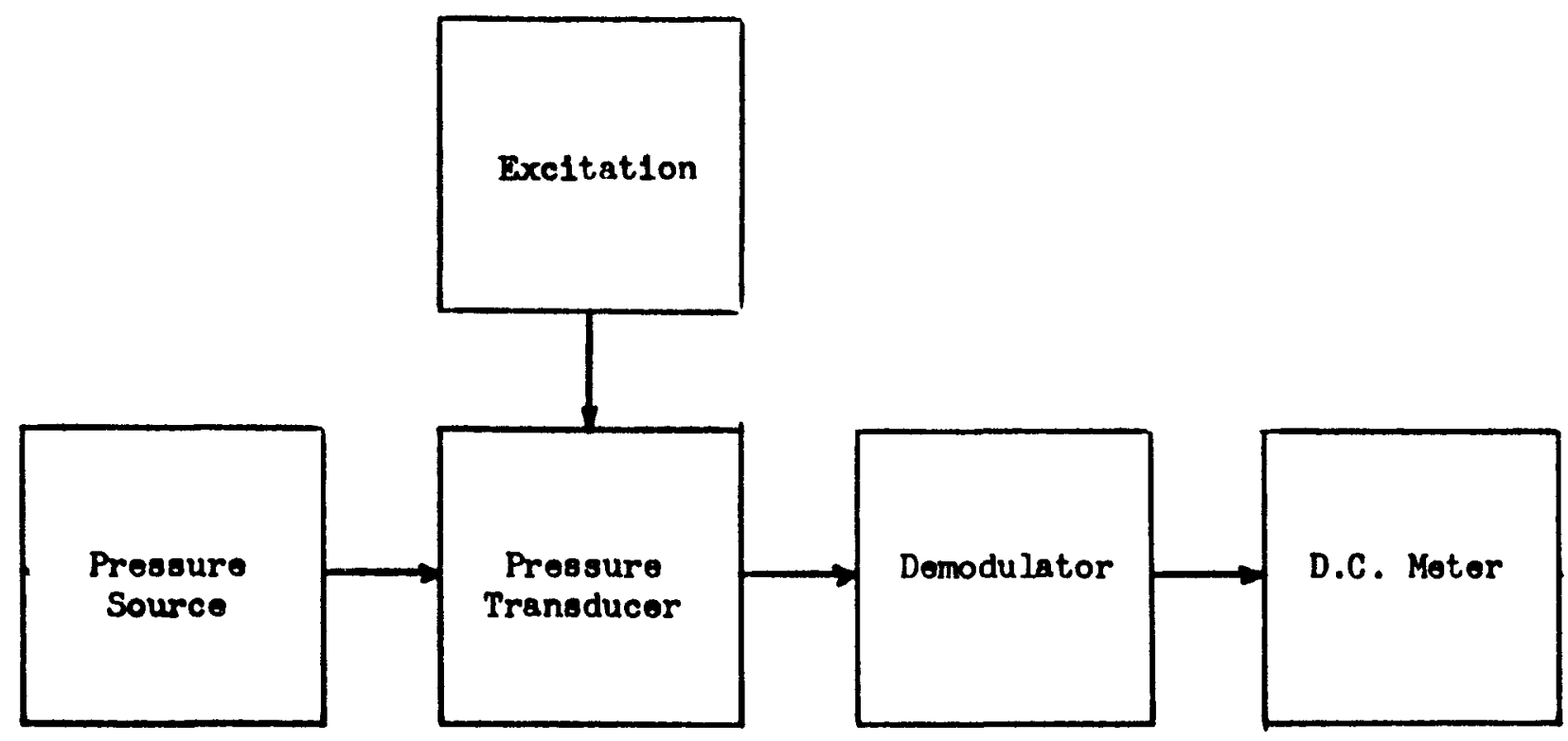

Figurel II

Strain Gage Typo Pressure Transducer

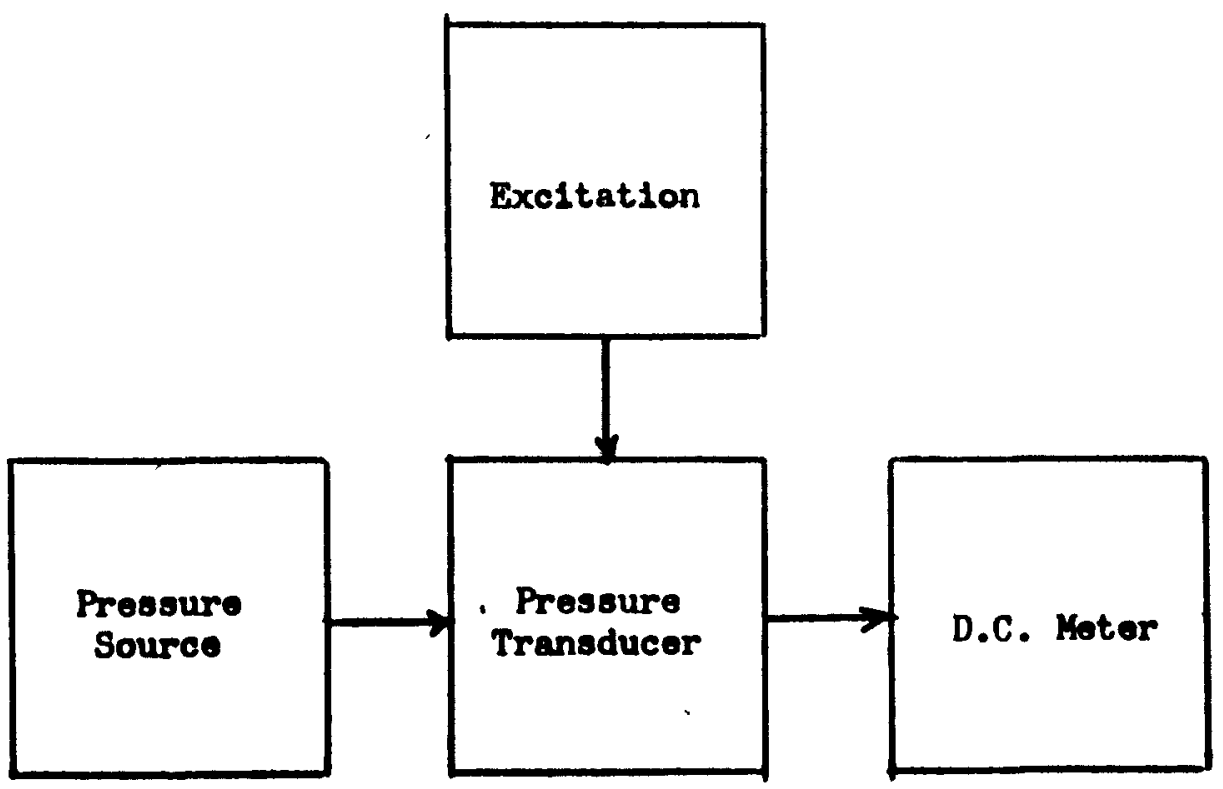

